\title{
INOVAÇÃO E SOBERANIA: A NECESSIDADE DO INVESTIMENTO ESTATAL EM P\&D - O INVESTIMENTO ESTATAL EM TECNOLOGIA COMO FORMA DE MANUTENÇÃO DE HEGEMONIA.
}

INNOVATION AND SOVEREIGNTY: THE NEED FOR STATE INVESTMENT IN R\&D - State investment in technology as a means of maintaining hegemony.

INNOVACIÓN Y SOBERANÍA: LA NECESIDAD DE LA INVERSIÓN DEL ESTADO EN P\&D - La inversión del Estado en tecnología como forma de mantener la hegemonía

\section{Felipe Chiarello de Souza Pintor}

\section{Kristian Rodrigo Pscheidt ${ }^{2}$}

1 Doutorado em Direito pela Pontifícia Universidade Católica de São Paulo, Brasil, membro do Conselho Técnico Científico, do Conselho Superior e do Comitê da Área do Direito da CAPESMEC, onde presidiu a Comissão de Classificação de Livros (2010) e (2012 - 2013). Atualmente é Professor da Graduação e do Programa de Mestrado e Doutorado em Direito Político e Econômico da Universidade Presbiteriana Mackenzie, Membro do Comitê da Área do Direito no Programa SciELO/ FAPESP, do Comitê Científico da Revista da ANPG: Ciência, Tecnologia e Políticas Educacionais, periódico científico institucional editado pela Associação Nacional de Pós-Graduandos e Membro do Conselho Editorial da Revista da Procuradoria-Geral do Banco Central, Parecerista na Área do Direito da CAPES-MEC e Secretário Adjunto do CONPEDI.

2 Professor dos cursos de graduação e pós-graduação em Direito pela Universidade Tuiuti do Paraná e da Faculdade CNEC Campo Largo, Doutorando e Mestre em Direito Político e Eco- 
Resumo: O Estado hoje é o ator central no desenvolvimento de tecnologias revolucionárias. Incentiva, financia e tem a paciência necessária para assumir os riscos de um investimento futuro e incerto. Porém, os objetivos desta atuação estatal vão muito além da geração de empregos ou arrecadação. Trata-se de assegurar vantagem na corrida militar, ficar na vanguarda dos movimentos econômicos e, principalmente, em uma Sociedade do Conhecimento, permitir que a sociedade que represente esteja na dianteira intelectual. A tecnologia, entendida como inovação, desvenda uma estratégia política econômica do Estado deter soberania em um ambiente mundial. Depende invariavelmente das instituições e, infelizmente, o Brasil ainda não percebeu essas variáveis.

Palavras-chave: Estado, Tecnologia, Sociedade do Conhecimento, Soberania, Hegemonia.

Abstract: The State today is the central player in the development of revolutionary technologies. It encourages, supports and has the patience needed to take risks of an uncertain future investment. However, the aims of this state action go far beyond the creation of jobs and tax. It is about ensuring military advantage, staying at the forefront of economic movements and, especially in a knowledge society, enabling the society it represents to lead the way intellectually. Technology, understood as innovation, unveils an economic political strategy of the State to retain sovereignty in a global environment. This invariably depends on the institutions and, unfortunately, Brazil has not perceived these variables.

Keywords: State, Technology, Knowledge Society, Sovereignty, Hegemony.

Resumen: El Estado es hoy el protagonista central en el desarrollo de tecnologías revolucionarias. Incentiva, financia y tiene la paciencia necesaria para asumir los riesgos de una inversión futura e nômico pela Universidade Presbiteriana Mackenzie (2014), possui L.L.M em Direito de Negócios pela FMU (2014), é especialista em Direito Tributário pelo Centro Universitário Curitiba (2010), possui graduação em Direito pela Pontifícia Universidade Católica do Paraná (2008) e graduação em Jornalismo pela Pontifícia Universidade Católica do Paraná (2004). 
incierta. Sin embargo, los objetivos de esa actuación del Estado van más allá de la generación de empleos o recaudación fiscal. Se trata de asegurar la ventaja en la carrera militar, estar en la vanguardia de los movimientos económicos y principalmente, en una Sociedad del Conocimiento, permitir que la sociedad que represente esté en la delantera intelectual. La tecnología, entendida como innovación, desvenda una estrategia política económica del Estado para poseer soberanía en un ambiente mundial. Depende invariablemente de las instituciones y, desgraciadamente, Brasil todavía no percibió esas variables.

Palabras clave: Estado; Tecnología; Sociedad del Conocimiento; Soberanía; Hegemonía.

\section{INTRODUÇÃO}

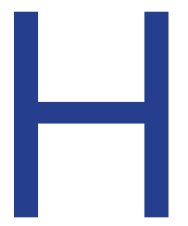

á uma forte tendência popular, referendada por autores de reputação3, em condenar o Estado como "caro, ineficiente e, sobretudo, disfuncional". Porém, neste ensaio, essa constatação é derrubada, pelo menos com referência aos Estados Unidos da América. Em cultuado livro denominado "O Estado Empreendedor: desmascarando o mito do setor público vs. setor privado"4, Mariana Mazzucato quebra o paradigma do Estado ocioso e obsoleto nos investimentos em Pesquisa e Desenvolvimento (P\&D). Enfoca que o setor privado, guiado por lucros e retornos a curto prazo, delega ao Estado o papel de principal financiador de programas de tecnologias revolucionárias. Assume-se o risco do fracasso, investe-se no incerto e, depois, o Estado ainda é criticado pela falta de eficiência, burocracia e morosidade de atuação.

De acordo com a Mazzucato (p. 94), "o alto risco e as características aleatórias do processo de inovação são alguns dos principais motivos para as empresas que maximizam os lucros investirem menos em pesquisa básica". Por isso esse tipo de investimento é realizado pelo Estado.

3 Neste sentido ver André Lara Resende. Devagar e simples: economia, Estado e vida contemporânea. São Paulo: Companhia das Letras, 2015, p. 191.

4 Trad. Elvira Serapicos. São Paulo: Portfolio Penguin, 2014. 
Cita como exemplos programas de financiamentos realizados pelo Governo Norte-Americano, como a DARPA (Agência de Projetos de Pesquisa Avançada de Defesa), NASA (National Aeronautics ans Space Agency), SBIR (Programa de Pesquisa para a Inovação em Pequenas Empresas), NNI (National Nanotechnology Initiative), $\mathrm{NHI}$ (National Institution of Health), entre outros, que deu origem a uma revolução tecnológica que viabilizou comercialmente produtos farmacêuticos, a internet, iPod, iPhone e iPad. Aqui no Brasil, destaca o papel das energias renováveis e o papel do BNDES (Banco Nacional de Desenvolvimento Econômico e Social) como agente financiador.

Não se pode desprezar esse raciocínio certo e rasteiro, talvez inspirado em estudos de diversos outros autores que diagnosticaram o papel fundamental do Estado no desenvolvimento de setores como computação, saúde e agricultura5; e que motivou uma série de novos estudos sobre o tema ${ }^{6}$, todos desvendando que "o Estado em si deve atuar como investidor 'paciente', de longo prazo".

No entanto, um elemento fundamental não foi devidamente percebido pela autora, que é a principal motivação para o investimento estatal em tecnologia: trata-se de manter a hegemonia socioeconômica da nação. Todos os cases citados estão umbilicalmente ligados à necessidade de a sociedade mostrar-se institucionalmente à frente dos outros Estados.

O papel político é central neste tema, como reconhecem Aldo Musacchio e Sergio Lazzarini” ao questionar se "seria importante estudar como os diferentes níveis de propriedade do Estado geram níveis mais altos de inovação, ou se as pressões de políticos, em busca de objetivos políticos ou outros de curto prazo atenuam esses esforços".

5 Ver Margareth B. W. Graham, "Entrepeneurship in the United States, 1920-2000". In D. S. Landres; J. Mokyr; W. J. Baumol (Orgs.), The Invention of the Enterprises: Entrepeneurship from ancient mesopotomia to modern times. Princeton: Princeton, University Press, 2010, pp. 401-402.

6 AGHION, Philippe et al. Innovation and Institutional Ownership. American Econommic Review, v. 103, n. 1, 2013, pp. 227-304.

7 n Reinventando o Capitalismo de Estado: O Leviatã nos negócios: Brasil e outros países. Trad. Afonso Celso da Cunha Serra. São Paulo: Portfolio Penguin, 2014, p. 339. 
É ingênuo pensar, como faz Mazzucato, que o Estado não leva qualquer vantagem ao investir em tecnologia inovadora. Não se trata apenas de garantir a geração de empregos e proceder com a arrecadação dos tributos inerentes à renda do setor que se beneficiou com os investimentos estatais. Os 304 mil empregos diretos e indiretos gerados pela Apple, por exemplo, e os tributos recebidos são importantes ${ }^{9}$, mas apenas laterais ao cerne da questão.

Interessante perceber que ela mesma cita a corrida tecnológica desenfreada em face do Japão e a necessidade de obter autonomia no desenvolvimento de hardwares e microchips para fins militares. De mais a mais, a internet, como forma de vencer eventual disputa nuclear frente à União Soviética. Igualmente, o desenvolvimento do GPS e das telas touch screen, todas vinculadas a programas militares americanos. A nanotecnologia, igualmente, no sentido de aprimorar o poderio militar americano.

Portanto, o desenvolvimento da tecnologia pelo Estado passa ao largo da simples geração de empregos e da ânsia arrecadatória, indo para campos de desenvolvimento socioeconômico, alavancagem do poderio financeiro e manutenção de sua hegemonia militar.

É neste sentido que o presente artigo pretende evoluir as ideias lançadas por Mariana Mazzucato, mas sob um enfoque crítico, porquanto o Estado é investidor, sim, mas seus propósitos superam a mera retórica de reconhecimento comercial dos investimentos realizados pelo Estado. O que se faz é manter-se na frente da corrida tecnológica e, somente assim, mostrar-se soberano em um novo cenário mundial.

\section{A ERA DO CONHECIMENTO}

Vive-se uma nova Era. Os teóricos dos próximos séculos, certamente, irão solapar o momento atual em contraposição ao Estado que se convencionou

8 Neste sentido veja a interrogação realizada por Mariana Mazzucato às fls. 127: "Por que o Estado não é recompensado pelos investimentos diretos em pesquisa básica e aplicada que levam a tecnologias bem sucedidas e servem de base para produtos comerciais revolucionários como o iPod, o iPhone e o iPad?".

9 Vide Mazzucato.... (2014), pp. 228-236. 
denominar de Contemporâneo, deflagrado pela Revolução Francesa de 1789. Trata-se de um novo estilo de pensar, agir e comunicar. É um novo tempo, em que o conhecimento está no centro das discussões do poder ${ }^{10}$.

A knowledge society (Sociedade do Conhecimento) é uma "forma específica de organização social em que a geração, o processamento e a transmissão da informação tornam-se fontes fundamentais de produtividade e poder, devido às novas condições tecnológicas surgidas nesse período histórico" ${ }^{11}$. É ínsita a atuação estatal, portanto, nesse novo momento histórico, surfar nas ondas daquilo que o deixará na vanguarda do poder e da realidade socioeconômica: a tecnologia.

Como destacado por Manuel Castells ${ }^{12}$, o que deve ser guardado para o entendimento da relação entre a tecnologia e a sociedade é que o papel do Estado, seja interrompendo, seja promovendo, seja liderando a inovação tecnológica, é um fator decisivo no processo geral à medida que expressa e organiza as forças sociais dominantes em um espaço e uma época determinada. $O$ conhecimento é um bem público puro, que deveria ser disseminado para a evolução da condição humana.

Essa sociedade apresenta características peculiares, colocando a tecnologia como o centro das atenções. As tecnologias se desenvolvem para permitir o homem atuar sobre a informação propriamente dita, ao contrário do passado, quando o objetivo dominante era utilizar informação para agir sobre as tecnologias, criando implementos novos ou adaptando-os a novos usos. Os efeitos das novas tecnologias têm alta penetrabilidade porque a informação é parte integrante de toda atividade humana, individual ou coletiva e, portanto, todas essas atividades tendem a ser afetadas diretamente pela nova tecnologia ${ }^{13}$.

10 Jorge WERTHEIN (In A sociedade da informação e seus desafios. Ci. Inf., Brasília, v. 29, n. 2, p. 71-77, maio/ago. 2000, p. 71), prefere utilizar a expressão "sociedade da informação", afirmando que esta "passou a ser utilizada, nos últimos anos desse século, como substituto para o conceito complexo de "sociedade pós-industrial" e como forma de transmitir o conteúdo específico do "novo paradigma técnico-econômico".

11 CASTELLS, Manuel. A sociedade em rede. 4. ed. São Paulo: Paz e Terra, 1999. v.1., p. 46.

12 Ob. Sup. Cit. p. 31. Conclui o autor afirmando que "em grande parte, a tecnologia expressa a habilidade de uma sociedade para impulsionar seu domínio tecnológico por intermédio das instituições sociais, inclusive o Estado. Portanto, a nova sociedade emergente desse processo de transformação é capitalista e também informacional, embora apresente variação histórica considerável nos diferentes países, conforme sua história, cultura, instituições e relação específica com o capitalismo global e a tecnologia informacional".

13 Castells (1999) ainda destaca que "há a crescente convergência de tecnologias, principalmente a microeletrônica, telecomunicações, optoeletrônica, computadores, mas também 
Tecnologia e conhecimento são, portanto, as constantes da sociedade atual. Aquele que detiver o domínio sobre essas variáveis terá o controle sobre os modos produção e de desenvolvimento intelectual. É o proprietário desse conhecimento quem estará na vanguarda dessa nova Era.

Não por menos que Robin Mansell e Uta Wehn ${ }^{14}$ dissertam sobre o acesso universal ao conteúdo e às fontes de conhecimento, apontando para a necessidade de resolver vários outros desafios, sendo o principal deles "convencer o governo e centros produtores de conhecimento financiados por recursos públicos a tornarem disponíveis ao público as informações produzidas". Estar na dianteira das inovações e do desenvolvimento do conhecimento é ter o domínio sobre os caminhos a serem percorridos pela sociedade atual. Cria-se assim uma nova cultura.

Portanto, pensar e discorrer sobre tecnologia nos dias atuais deve tomar em consideração essa primeira e imprescindível variável: a sociedade do conhecimento. Centrar as verificações sobre inovação unicamente no ambiente econômico levará incorrer o doutrinador em erro, pois hegemonia não se constrói unicamente pelo viés financeiro, muito embora hoje seja também indispensável.

O VIÉS MILITAR

De igual modo, não se pode pensar em tecnologia e inovação sem considerar um viés relacionado à hegemonia militar. Como enfatiza Francis Fukuyama ${ }^{15}$, a tecnologia confere, também, alargamento das vantagens militares decisivas aos países que a possuem, oferece possibilidades de produção econômica e acúmulo de riqueza, bem como estabelece diferenciações nas condições de relacionamento no sistema internacional.

A hegemonia militar é um dos pilares para a conquista socioeconômica mundial. Um país submisso, sem condições de fazer respeitar-se pela força, jamais logrará

e crescentemente, a biologia. O ponto central aqui é que trajetórias de desenvolvimento tecnológico em diversas áreas do saber tornam-se interligadas e transformam-se as categorias segundo as quais pensamos todos os processos".

14 In Knowledge societies: information technologies for sustainable development. Oxford: Oxford University, 1998.

15 FUKUYAMA, Francis. O Fim da História e o último homem. Rio de Janeiro, Rocco: 1992. 
êxito em uma missão de conquista hegemônica. É a lógica de Carl Schmitt ${ }^{16}$ repetida também, na Sociedade do Conhecimento, por François Chesnais ${ }^{17}$ ao afirmar que a orientação de boa parte do orçamento científico e militar para o campo de pesquisa e desenvolvimento garante a liderança tecnológica e estabelece uma diferença importante ao assinalar a hierarquia conquistada e a amplitude dos meios postos em ação pelos Estados Unidos. O objetivo é a preservação das relações de dominação política e social e os modos de vida determinantes na acumulação de capital.

Não se trata de mero acaso ou consequência da II Guerra Mundial. Trata-se de um planejamento estratégico bem-sucedido realizado pelos Estados Unidos da América. A internet, o GPS, touch screen ou a própria nanotecnologia são direcionados aos objetivos militares. A internet, exemplo mais enfático, tinha como objetivo viabilizar um sistema de comunicações que não pudesse ser interrompido por avarias locais. Em época de Guerra Fria, a preocupação dos militares era uma rede de telecomunicações que não possuísse uma central e que não pudesse ser destruída por nenhum ataque localizado.

Como indica Richard Nelson ${ }^{18}$, a liderança americana nos primeiros anos do pósguerra indica o investimento "em indústrias de alta tecnologia, era nova, e refletia os maciços investimentos privados e públicos em pesquisa e desenvolvimento e no ensino científico e técnico".

As indústrias de alta tecnologia contam com maciço apoio orientado por um empreendimento militar voltado para alçar os Estados Unidos à condição de potência militar global inquestionável ${ }^{19}$. Trata-se do complexo institucional que foi responsável por estimular tanto a demanda quanto a oferta ao processo de inovações.

16 Uma das formulações mais conhecidas de Carl Schmitt sobre soberania está presente logo no início de seu livro "Teologia política" enunciando que "Soberano é aquele que decide do estado de exceção" (in Théologie politique. Paris: Gallimard, 1988, p. 15).

17 CHESNAIS, François. After the stock market turnabout: questions and hypotheses. Paris: Université Paris, 2003.

18 NELSON, Richard. As fontes do crescimento econômico. Campinas: Editora Unicamp, 2006, p. 372.

19 MEDEIROS, Carlos A. O Desenvolvimento Tecnológico Americano no Pós-Guerra como um Empreendimento Militar. In: Fiori, José L. O Poder Americano. Petrópolis: Vozes, 2004. 
A rede de instituições voltadas à pesquisa e ao desenvolvimento promoveu a aceleração do progresso tecnológico no país, tendo como preocupação a segurança nacional. A liderança política e econômica do país é sustentada pelo desenvolvimento tecnológico baseado, principalmente, nas condições oferecidas por seu complexo industrial militar, conclui Moreira $\mathrm{Jr}^{20}$.

Perceba-se que a tônica militar é fator preponderante no investimento em inovação, mas outro fator é ainda primordial. É preciso ter instituições que movimentem os investimentos e os justifiquem. Não basta financiar, mas também criar mecanismos de desenvolvimento da inovação.

\section{NÃO BASTA FINANCIAR A TECNOLOGIA}

Nesta sociedade do conhecimento evidencia-se o estreito relacionamento entre o desenvolvimento das instituições e o sucesso das inovações trazidas com investimentos Estatais em tecnologia, nitidamente com um viés militar. Investir, no entanto, sem um planejamento adequado, não garante o sucesso de nenhum empreendimento, nem mesmo na área da inovação.

Essa percepção é verificada ainda em 1995 por Joseph L. Bower e Clayton Christensen ao dissertarem sobre a "inovação disruptiva"21, indicando que as companhias perdem a liderança justamente quando não investem em tecnologias inéditas capazes de criar novos mercados. De acordo com os autores, os pontoschave para a prosperidade em uma mudança disruptiva não é simplesmente assumir mais riscos, realizar investimentos no longo prazo ou evitar a burocracia. Trata-se em verdade de organizar a decisão em investimento em tecnologia dentro de um contexto histórico, pensando-o como um negócio de mercado.

Evoluindo essas ideias, Joel Mokyr ${ }^{22}$ indica que existem basicamente três formas de uma economia crescer. Além de acumular o capital ou expandir o

20 MOREIRA JR, Hermes. Inovação, Militarismo e Hegemonia: o complexo industrial militar na estratégia dos Estados Unidos para a manutenção da liderança internacional. Revista OIKOS: Rio de Janeiro, 2014, p. 36.

21 BOWER, Joseph L.; CHRISTENSEN, Clayton M. Disruptive Technology: catching the wave. Harvard Business Review. May/Jun95, Vol. 73 Issue 3, p. 53.

22 MOKYR, Joel. Thinking About Technology and Institutions. Macalester International: Vol. 13, Article 8, 2003; 
mercado, a tecnologia está no centro do desenvolvimento econômico no Século XXI. Na sua forma básica, o conhecimento tecnológico ${ }^{23}$ se resume a instruções de como resolver um problema; mas não é esse o sentido da tecnologia hoje verificada junto à economia. A ciência oferece um retorno positivo à sociedade minimamente por três formas básicas ${ }^{24}$.

Primeiro está o "foco nos problemas" e é verificado quando uma demanda alimenta a busca pela solução perante os cientistas, formando um círculo virtuoso na tentativa de resolução do dilema. Em um segundo momento mostrase a "revelação artificial", verificável no desenvolvimento de novas tecnologias, permitindo desvendar novos horizontes e fronteiras do conhecimento como o estudo dos micro-organismos ou do universo. Por último, cita-se a "retórica do conhecimento", que é a tecnologia integrada ao dia a dia da pessoa, a qual passa a exigir o desenvolvimento e o barateamento das inovações, massificando-a.

Na visão de Joel Mokyr ${ }^{25}$, no entanto, o que torna a tecnologia um fator de sucesso é a transformação em um modelo de inovação institucional. As instituições são fundamentais. Há uma cooperação mútua entre a tecnologia e o mercado. As instituições auxiliam a tecnologia em projetos que promovem o desenvolvimento do Estado e da própria tecnologia. São quatro os momentos em que as instituições atuam de forma direta no desenvolvimento tecnológico:

- Forma uma agenda de pesquisa, evitando que esforços e investimentos sejam alocados em pesquisas que não irão promover uma melhoria efetiva nos padrões socioeconômicos;

- Reforça o vínculo entre aqueles que criam a tecnologia com os consumidores, colocando-os como essenciais no dia a dia das pessoas;

- Compensa aqueles que investem e promovem a tecnologia, seja mediante o pagamento de royalties ou protegendo a produção intelectual;

23 Para Joel Mokyr, o conhecimento não segue a lógica matemática pela soma aritmética, pois as pessoas não assumem o conteúdo para depois evoluir; isso exige um investimento sempre na base da educação. Também informa que se trata de um bem público que se uma pessoa adquire não significa que a outra também o terá.

24 MOKYR, Joel. 2003, pp. 15-17.

25 MOKYR, Joel. Thinking About Technology and Institutions. Macalester International: Vol. 13, Article 8, 2003, pp. 19-24; 
- Promove a massificação do conhecimento, criando uma demanda necessária e suficiente e alavanca mais investimentos no setor.

Assim, as instituições dirigem a inovação para aquilo que tenha relevância socioeconômica. Nessa relação de benefícios mútuos, a tecnologia cria um mercado novo para as instituições operarem. Cita-se como exemplo a abertura de um novo mundo com as navegações do Século XV, com o desenvolvimento industrial do Século XVIII, que criou um novo contexto de crescimento econômico e, já no Século XX, com o telégrafo e as ferrovias que promoveram a integração dos Estados Unidos da América.

Essa verificação redunda que a tecnologia é um fator de crescimento e desenvolvimento da economia ao longo dos tempos ${ }^{26}$. Porém, um país não é mais rico simplesmente porque investe mais em tecnologia, mas sim porque possui instituições que promovem a inserção dessa inovação como relevante e importante no contexto do Estado. E dentro dessa lógica de cooperação entre as instituições e a tecnologia o resultado tem sido o desenvolvimento de ambos.

Mesmo as críticas sobre a extinção do ser humano no mercado de trabalho não se mostram consistentes, tal como afirma Joel Mokyr et al. ${ }^{27}$, ao refutarem afirmando que, no curto prazo, há uma certa diminuição dos postos de trabalho, mas no longo prazo há uma sensível melhora em virtude da criação de um nicho de mercado mais qualificado e especializado.

Esse vínculo entre o desenvolvimento tecnológico e as instituições novamente reforça o papel do Estado, que é uma instituição "que se realiza e dura, juridicamente, num meio social"28. Deve-se atentar, ainda, que Estado não é a 26 "If we were to ask why Germany is richer today than 1815, the importance of technologybecomes unassailable - thought better institutions might still be of importance as well. The statements are thus of degree, not of absolutes; but in economic history degree is everything" (MOKYR, 2003, p. 29).

27 VICKERS, Chris, ZIERBATH, Nicolas. The history of technological anxiety and the future of economic growth: is this time different? Journal of Economic Perspectives. Vol. 29. N. 3. 2015, pp. 31-50.

28 HAURIOU, Maurice. La Theorie de L'Institucion et de la Fondation. Cahiers de la Nouvelle Journée, $N^{\circ} 4$, 1925, p. 10. Continua o autor enunciando que, "para a realização desta ideia, um poder se organiza e lhe propicia os seus órgãos; de outro lado, entre os membros do grupo social interessado na realização da ideia, surgem manifestações de comunhão dirigidas pelos órgãos do poder e regulamentadas por meio de procedimentos estabelecidos" (HAURIOU, 1925, p. 10). 
única instituição existente no meio social, sendo que organizações regionais, complexos empresariais, organizações civis, sindicatos, entre outros, também são instituições que manipulam forças políticas para ganhar personalidade ${ }^{29}$.

Verifica-se aí um complexo de instituições trabalhando um conjunto para que a inovação tecnológica desenvolva-se com o objetivo de manter ou promover o desenvolvimento pleno da sociedade regional. O Estado certamente é o elemento primordial, mas não se pode pensar nele sem considerar os demais grupos de interesse que atuam no setor.

Conforme Ronaldo Fiani, $^{30}$ no cenário socioeconômico interagem não apenas grupos de interesse, mas também "vários agentes reguladores com objetivos políticos próprios, mediados por um quadro institucional que delimita e define suas responsabilidades e as possibilidades de intervenção desses agentes reguladores e dos grupos de pressão". De tal maneira, o Estado é interferido por diversos atores institucionais, e o desenvolvimento tecnológico deste certamente redunda no benefício mútuo daqueles que o financiam.

\section{TECNOLOGIA E SOBERANIA}

Está claro que o propósito dos investimentos estatais em inovação não se resume à geração de empregos e arrecadação. Promover o fortalecimento da economia, abrindo novos mercados, e assegurar que a hegemonia militar seja mantida, é o escopo do Estado ao investir em tecnologia em uma Sociedade do Conhecimento. E tais tecnologias são deliberadamente insculpidas no mercado privado para que se renove o ciclo de inovação. Sem um mercado que exija novidades, a tendência é contentar-se com a obsolescência. De tal forma, as instituições que atuam em conjunto com o Estado também se desenvolvem, formando uma rede de cooperação virtuosa.

29 Neste sentido, Maurice Hauriou (in An interpretation of the principles of public law. Harvard Law Review. Vol. XXXI. n. 06, 1918, p. 814) enuncia que "the state is not the only corporate institution. We have incorporated municipalities, business, trade unions, etc. Briefly, there is a whole class of incorporated moral persons of which the state is only a peculiarly interesting variety. The central theory of public law must then be corporate institutions with its internal constitutions".

30 In Afinal, a quais interesses serve a regulação? Revista Economia e Sociedade, Campinas, v. 13 , n. 2 (23), p. 81-105, jul./dez. 2004, p. 82. 
Segundo Lévy ${ }^{31}$, em princípio, as atividades de produção de bens e serviços deveriam ter por objetivo o enriquecimento do humano, como: aumentar as competências dos indivíduos e grupos, promover a sociabilidade e o reconhecimento recíproco, proporcionar as ferramentas de autonomia, criar a diversidade, variar os prazeres, etc. No entanto, o que talvez fosse apenas um imperativo moral, logo facultativo, para as finalidades da economia clássica, tende a tornar-se uma obrigação, uma condição de sucesso.

Com efeito, a contínua transformação das técnicas, dos mercados e do meio econômico, na visão do autor 32 , "leva os coletivos a abandonar seus modos de organização rígidos e hierarquizados, a desenvolver a capacidade de iniciativa e de cooperação ativa de seus membros". E nada disso seria possível a menos que envolva e mobilize efetivamente a subjetividade dos indivíduos com uma nova atuação voltada para o humano como tal. É como se o humano, em toda a sua extensão e variedade, voltasse a se tornar matéria-prima.

Há uma comunhão de interesses, entretanto, que nem sempre estão ligados ao bem-estar da população. Como afirma Moreira Jr. ${ }^{33}$, uma breve inflexão na literatura é capaz de indicar que cada Estado para assumir a condição de "líder" ou potência hegemônica em seu contexto "apresentou algum modelo de inovação tecnológica (aliado ao modelo de organização política de sua economia), que Ihe garantiu um salto qualitativo em relação a seus pares. Dessa forma, os países centrais utilizam suas vantagens em inovação e difusão de tecnologia para a manutenção do sistema centro-periferia dentro de uma economia-mundo integrada ou em competição".

De tal maneira, o investimento em inovação promovido pelo Estado está vinculado à nova noção de soberania mundial, não mais restrito ao território local. Trata-se de ser onipotente em todo o território mundial, o que se faz no âmbito cultural, militar e econômico; e tal objetivo somente por ser alcançado

31 LÉVY, P. A inteligência coletiva: por uma antropologia do ciberespaço. Tradução de Luiz Paulo Rouanet. São Paulo: Ed. Loyola, 1998, p. 41.

32 O. Sup. Cit. p. 42.

33 MOREIRA JR., Hermes. Inovação, Militarismo e Hegemonia: o complexo industrial militar na estratégia dos Estados Unidos para a manutenção da liderança internacional. OIKOS | Rio de Janeiro | Volume 13, n. 1 • 2014 | www.revistaoikos.org | págs. 22-39 
com a tecnologia. A soberania não se resume mais como sendo a "entidade que não conhece superior na ordem externa nem igual na ordem interna"34.

Investir em tecnologia, como aquela desvendada por Mariana Mazzucato, se constitui em uma agenda institucional voltada para uma missão bastante clara: promover, manter e fazer perpetuar a hegemonia internacional dos Estados Unidos da América e as diversas instituições que o circulam.

\section{O NOVO ESTADO CAPITALISTA}

A acepção de um Estado Empreendedor, conforme Mazzucato ${ }^{35}$, que detém uma atuação ativa no desenvolvimento tecnológico, desvendou-se ainda mais factível com a queda do neoliberalismo. A crise financeira de 2008-2009 comprovou que o Estado nunca deixou de ser o protagonista no desenvolvimento de uma nação. Vive-se um "processo de transição do liberalismo econômico, que fracassou novamente em 2008, para o novo desenvolvimentismo"36.

O Estado se consolida como investidor majoritário e minoritário em setores estratégicos. Mesmo com a transferência de ativos para proprietários privados, o Estado continua presente na economia, como maneira de preservar ligações com o setor produtivo ou minimizar a oposição pública às atuações do Governo. Em verdade, o envolvimento do Estado na economia ajuda o governo não só a resolver numerosas falhas de mercado, desde a necessidade de coordenar os investimentos até o desejo de realizar objetivos sociais, ala da pura maximização lucro, mas se trata de "uma preferência ideológica pela intervenção do Estado na economia ou de política nacionalista"37.

34 Propugnada por Jean Bodin na sua obra "Os Seis livros da República".

35 O termo Empreendedor é justificado por Mariana Mazzucato em diversas ocasiões. Cita-se o trecho abaixo como referência: "O Estado... 'totalmente' desenvolvendo inovações? Sim, a maioria das inovações radicais, revolucionárias, que alimentaram a dinâmica do capitalismo - das ferrovias à internet, até a nanotecnologia e farmacêutica modernas - aponta para o Estado na origem dos investimentos 'empreendedores ' mais corajosos, incipientes e de capital intensivo" (2014, p. 26).

36 Conforme BRESSER-PEREIRA, Luiz Carlos. A Construção política do Brasil: sociedade, economia e Estado desde a Independência. São Paulo: Editora 34, 2014, p. 406.

37 MUSACCHIO, Aldo, LAZZARINI, Sergio. Reinventando o Capitalismo de Estado: o Leviatã nos negócios: Brasil e outros países. Trad. Afonso Celso da Cunha Serra. São Paulo: Portfolio Penguin, 2014, p. 75. 
Nas palavras de Gérard Duménil e Dominique Lévy38 (2013, p. 12), esse Capitalismo de Estado "será mais multipolar que a atual e, ademais, se essas mudanças não forem bem sucedidas nos Estados Unidos, o declínio de sua hegemonia internacional deverá se acentuar". E para piorar, o que se verifica é que a configuração oculta no topo da hierarquia social oferece a base robusta para que surjam mudanças; "embora não favoráveis às classes populares". O quadro geral, portanto, demonstra uma tendência do estabelecimento no topo das hierarquias sociais de um novo compromisso de centro-direita, e não de centro-esquerda, pois se mostra um quadro de fraqueza das lutas populares em um Estado intervencionista ${ }^{39}$.

Verifica-se, ao longo do século XX e início do século XXI, uma importância crescente do Estado em todas as esferas da vida em sociedade e da economia. O mesmo atua diretamente na área social da saúde, educação, distribuição de renda ${ }^{40}$. Novamente o Estado está afetando diversos setores, como o bélico e o energético, as empresas estatais que concorrem com as privadas, os fundos de pensão, os fundos de riqueza soberanos, os financiamentos estatais, etc.

E a tecnologia detém o papel central na Sociedade do Conhecimento, a qual irá configurar um novo Estado. Como afirma John Micklethwait e Adrian Wooldridge ${ }^{41}$, "a crise do Estado ocidental e a expansão do Estado emergente estão chegando em uma época favorável: novas tecnologias oferecem a chance de melhorar o governo radicalmente, tanto quanto se perguntar velhas questões, incluindo a mais fundamental: para que serve o Estado?".

Os Estados Unidos da América possuem uma visão muito clara do que é preciso fazer para manter seu status no cenário internacional. E todas as alternativas verificadas, seja no âmbito militar ou econômico, incluem a tecnologia como o ponto central. Ela é o motor dessa nova Era.

38 In A crise do neoliberalismo. São Paulo: Biotempo, 2013, p. 12.

39 Ob. Sup. Cit. p. 348

40 COSTA, Natalia Nunes. Capitalismo de Estado no Brasil: uma análise crítica das transformações do estado brasileiro na última década. Revista da Graduação da PUC/RS. V. 6, n. 2, Porto Alegre, 2013, p. 26.

41 In A quarta revolução: a corrida global para reinventar o Estado. São Paulo: Portfolio Penguin, 2014, p. 25. 
Ocorre que os EUA não estão sozinhos neste contexto. Evidências indicam que a China já produz de forma independente armas com a utilização de tecnologia de ponta ${ }^{42}$. De igual forma, o Estado Oriental cada vez mais é estudado como modelo a ser seguido, em especial Hong Kong, tido como um sucesso de administração pública calcada em preceitos de qualificação do gestor público. Homenageiamse, perigosamente, governos não totalmente democráticos, como fazem John Micklethwait e Adrian Wooldridge ${ }^{43}$.

O Brasil está na vanguarda dos investimentos em tecnologia verde e conta com um dos bancos de desenvolvimento mais comentados do mundo ${ }^{44}$, que é o BNDES. Conforme Relatório de Gestão de $2014{ }^{45}$, somente nesse ano foram desembolsados $\mathrm{R} \$ 187,8$ bilhões, sendo $\mathrm{R} \$ 5,9$ bilhões em inovação e $\mathrm{R} \$ 28,3$ bilhões em economia verde. Foram 1.130.202 operações com 277.085 clientes. O Brasil, ainda, possui recursos naturais, especialmente a Amazônia, hídricos e minerais necessários e suficientes para torná-lo soberano frente às economias mundiais. Detém uma vasta área agrícola e um mercado consumidor de 200 milhões de habitantes.

Surge então a questão: por que o Brasil ainda é um ator lateral em se tratando de inovação? Por que autores como André Lara Resende ${ }^{46}$ destacam o Brasil tendo como "único objetivo viabilizar a expansão de seu poder e de suas áreas de influência"? A resposta a esses questionamentos envolvem a digressão a elementos que fogem ao objetivo deste em ensaio, uma vez que não existe resposta única. Não há um consenso.

Entretanto, diante das premissas indicadas neste artigo, é possível extrair uma das causas: a fragilidade e o descrédito das instituições que deveriam promovem 42 Neste sentido Reuben F. Johnson (In China builds its own high-tech military. Washington Times, The (DC). 09/22/2010, p7-7. 1) ao afirmar que "China's military is nearly self-sufficient in building advanced weaponry following decades of importing aircraft, ships, submarines and missile technology, mainly from Russia, and the capability is raising new fears of Chinese military hegemony in Asia and arms exports to rogue states.

43 In A quarta revolução: a corrida global para reinventar o Estado. São Paulo: Portfolio Penguin, 2014.

44 Elogiados tanto por Mariana Mazzucato, quanto por Aldo Musacchio e Sergio Lazzarini, nas obras citadas neste artigo.

45 In BNDES. Relatório Anual 2014. Disponível em: http://www.bndes.gov.br/SiteBNDES/export/sites/ default/bndes_pt/Galerias/Arquivos/empresa/RelAnual/ra2014/RA_2014.pdf. Acesso em: 17 out. 2015.

46 In Devagar e simples: economia, Estado e vida contemporânea. São Paulo: Companhia das Letras, 2015, p. 191. 
o desenvolvimento do país. Especialmente diante das considerações de Ronaldo Fiani $^{47}$ ao indicar que as instituições detêm um papel-chave no desenvolvimento, pois "possuem uma função muito importante nas sociedades, em particular as sociedades em desenvolvimento: determinar as possibilidades e formas em que podem acontecer tanto a cooperação quanto o conflito".

Como traz Joel Mokyr, o sucesso dos investimentos em inovação depende imprescindivelmente de instituições perenes que criem condições, mercado e oportunidades de crescimento tecnológico. É necessário estar ciente que se vivencia uma Sociedade do Conhecimento, que deve pautar-se pela criação de uma agenda de pesquisa, evitando esforços inúteis; reforçar o vínculo entre aqueles que criam a tecnologia com os consumidores; recompensar aqueles que investem e promovem a inovação; promover a massificação do conhecimento, criando uma demanda necessária e suficiente; e alavancar mais investimentos no setor.

De tal sorte, o que se verifica na prática são políticas e atuações desconexas. Enquanto de um lado se promove o investimento em tecnologia, demora-se mais de cinco anos para o registro de uma patente; investe-se em tecnologia verde, no entanto, sustenta-se sua indústria de base no petróleo; incentivamse os investimentos em infraestrutura, mas existe uma das cargas tributárias mais elevadas do mundo para o setor; pugna-se por incentivos nas áreas de tecnologia, mas se oneram sensivelmente aqueles que irão adquirir e aplicar essas tecnologias (licenças, alvarás e autorizações). Pugna-se por qualificação técnica, mas se reduzem créditos para as instituições de ensino; criam-se mecanismos de fomento à indústria, mas se adota uma política de juros que torna o crédito inviável; pauta-se pelo desenvolvimento tecnológico, mas se maneja a infraestrutura para dar cabo a uma lógica agroexportadora. Em verdade, são inúmeros os exemplos.

Assim é que o estudioso que pretender aprofundar o motivo do subdesenvolvimento do Brasil, necessariamente, deve ter como foco a fragilidade

47 In Cooperação e conflito. Instituições e desenvolvimento econômico. Rio de Janeiro: Elsevier, 2011, p. 10. Continua o autor explicando que "o sucesso das instituições na promoção do desenvolvimento, por sua vez, depende da medida em que elas conseguem oferecer possibilidades de solução para os conflitos e incentivar a cooperação, sem que o desenvolvimento enfrente grandes obstáculos". 
ou os reais interesses de suas instituições. $E$ isso é ainda mais evidente no momento atual do país, em que essas instituições são colocadas em xeque pelos protestos populares; e cada vez mais os escândalos de corrupção comprovam os reais propósitos daqueles que deveriam fazer o Brasil evoluir.

\section{CONSIDERAÇÕES FINAIS}

O Estado não é mais obsoleto, burocrata e ineficaz. Ou nunca foi? É certo que as críticas realizadas pelos liberais, e depois pelos neoliberais, ao papel exercido pelo Estado, não se confirmou. As constantes crises do capitalismo comprovam que, a cada ruptura do modelo liberal, surge o Estado para amparar e reequilibrar o sistema. Ele é um ator importante no desenvolvimento socioeconômico.

E a tecnologia é um dos principais fatores para o desenvolvimento do Estado. Ela é o motor que coloca uma nação à frente das demais, o elemento essencial para a hegemonia militar e o pilar central de uma Sociedade do Conhecimento. Tecnologia liga-se aos imperativos de soberania e hegemonia militar. Geração de empregos e arrecadação de tributos são efeitos desejáveis, mas não centrais ao escopo estatal.

Porém, a tecnologia por si só não é suficiente para alavancar uma nação; é necessário um planejamento e uma agenda congruente de medidas que alavanquem a tecnologia a um produto inovador. As instituições detêm um papel fundamental. Por certo, o Estado é a instituição maior, mas que precisa estar em consonância com os demais atores sociais.

Esse é o problema verificado no Brasil, em que há um investimento considerável em tecnologia e há um vasto potencial de desenvolvimento, mas as constantes mudanças e as crises político-econômicas esfacelam ideias preconcebidas. A inovação realizada pelo Estado possui a característica de ser incerta e a longo prazo. Mudanças institucionais constantes não dão o tempo necessário para a inovação se consolidar. Desta forma, multiplicam-se as políticas contraditórias.

Ocorre que esse cenário nunca foi novidade ${ }^{48}$, o que pode levar à conclusão 48 Já em 2006, Matias Pereira (in Finanças Públicas: A política orçamentária no Brasil. $3 a$ edição, São Paulo: Editora Atlas, 2006) observava que existe uma visível e crescente perda 
de que o objetivo é manter o cenário político-econômico exatamente como está. Mas a ortodoxia liberal, como assinala Luiz Carlos Bresser-Pereira ${ }^{49}$, já não é mais hegemônica. Os tempos são de mudanças.

\section{REFERÊNCIAS DAS FONTES CITADAS}

AGHION, Philippe et al. Innovation and Institutional Ownership. American Econommic Review, v. 103, n. 1, 2013;

BAGNOLI, Vicente. Direito e Poder Econômico. São Paulo: Campus, 2008;

BANCO NACIONAL DE DESENVOLVIMENTO ECONOMICO E SOCIAL. Relatório Anual 2014. Disponível em: <http://www.bndes.gov.br/SiteBNDES/export/sites/ default/bndes_pt/ Galerias/Arquivos/empresa/RelAnual/ra2014/RA_2014.pdf> Acesso em: 17 out. 2015;

BODIN, Jean. Le Six Livres de La Republique. Livro I, Cap. VIII. Jacques du Puis, 1583;

BRESSER-PEREIRA, Luiz Carlos. A Construção política do Brasil: sociedade, economia e Estado desde a Independência. São Paulo: Editora 34, 2014;

BOWER, Joseph L.; CHRISTENSEN, Clayton M. Disruptive Technology: catching the wave. Harvard Business Review. May/Jun95, Vol. 73 Issue 3, p172-172. 2/3p.;

CASTELLS, Manuel. A sociedade em rede. 4. ed. São Paulo: Paz e Terra, 1999. v.1;

CHESNAIS, François. After the stock market turnabout: questions and hypotheses. Paris: Université Paris, 2003;

COSTA, Natalia Nunes. Capitalismo de Estado no Brasil: uma análise crítica das transformações do estado brasileiro na última década. Revista da Graduação da PUC/RS. V. 6, n. 2, Porto Alegre, 2013;

DUMENIL, Gerard, LÉVY, Dominique. A crise do neoliberalismo. São Paulo: Biotempo, 2013;

FIANI, Ronaldo. Afinal, a quais interesses serve a regulação? Revista Economia e Sociedade, Campinas, v. 13, n. 2 (23), p. 81-105, jul./dez. 2004;

de credibilidade nas instituições brasileiras, que tem sido provocada de formas consciente e inconsciente, por inúmeros dirigentes governamentais nos três poderes da república. Esses dirigentes, no esforço de criar as condições para permanecer no poder ou obter ganhos políticos, têm se posicionado de forma contrária às instituições brasileiras, desconsiderando que o desenvolvimento socioeconômico e a democracia necessitam de instituições consolidadas.

49 In A Construção política do Brasil: sociedade, economia e Estado desde a Independência. São Paulo: Editora 34, 2014, p. 406. 
Cooperação e conflito. Instituições e desenvolvimento econômico. Rio de Janeiro:

Elsevier, 2011, p. 10;

FUKUYAMA, Francis. O Fim da História e o último homem. Rio de Janeiro, Rocco: 1992;

GRAHAM, Margareth B. W. Entrepeneurship in the United States, 1920-2000. In D. S. Landres; J. Mokyr; W. J. Baumol (Orgs.), The Invention of the Enterprises: Entrepeneurship from ancient mesopotomia to modern times. Princeton: Princeton, University Press, 2010

HAURIOU, Maurice. La Theorie de L'Institucion et de la Fondation. Cahiers de la Nouvelle Journée, $N^{\circ} 4,1925$, p. 2-45;

An interpretation of the principles of public law. Harvard Law Review. Vol. XXXI.

n. 06,1918 , pp 813-821;

JOHNSON, Reuben F. China builds its own high-tech military. Washington Times, The (DC). 09/22/2010, p7-7. 1;

LÉVY, P. A inteligência coletiva: por uma antropologia do ciberespaço. Tradução de Luiz Paulo Rouanet. São Paulo: Ed. Loyola, 1998;

MANSELL, Robin, WEHN, Uta. Knowledge societies: information technologies for sustainable development. Oxford: Oxford University, 1998;

MATIAS PEREIRA, J. Finanças Públicas: A política orçamentária no Brasil. $3^{a}$ edição, São Paulo: Editora Atlas, 2006;

MAZZUCATO, Mariana. O Estado Empreendedor: desmascarando o mito do setor público vs. setor privado. Trad. Elvira Serapicos. São Paulo: Portfolio Penguin, 2014;

MEDEIROS, Carlos A. O Desenvolvimento Tecnológico Americano no Pós-Guerra como um Empreendimento Militar. In: FIORI, José L. O Poder Americano. Petrópolis: Vozes, 2004.

MICKLETHWAIT, John, WOOLDRIDGE, Adrian. A quarta revolução: a corrida global para reinventar o Estado. São Paulo: Portfolio Penguin, 2014;

MOKYR, Joel. Thinking About Technology and Institutions. Macalester International: Vol. 13, Article 8, 2003;

VICKERS, Chris, ZERBATH, Nicolas. The history of technological anxiety and the future of economic growth: is this time different? Journal of Economic Perspectives. Vol. 29. N. 3. 2015, pp. 31-50;

MOREIRA JR, Hermes. Inovação, Militarismo e Hegemonia: o complexo industrial militar na estratégia dos Estados Unidos para a manutenção da liderança internacional. Revista OIKOS: Rio de Janeiro, 2014; 
MUSACCHIO, Aldo, LAZZARINI, Sergio. Reinventando o Capitalismo de Estado: O Leviatã nos negócios: Brasil e outros países. Trad. Afonso Celso da Cunha Serra. São Paulo: Portfolio Penguin, 2014;

NELSON, Richard. As fontes do crescimento econômico. Campinas: Editora Unicamp, 2006;

RESENDE, André Lara. Devagar e simples: economia, Estado e vida contemporânea. São Paulo: Companhia das Letras, 2015;

SCHMITT, Carl. Théologie politique. Paris: Gallimard, 1988;

WERTHEIN, Jorge. A sociedade da informação e seus desafios. Ci. Inf., Brasília, v. 29, n. 2, p. 7177, maio/ago. 2000;

Recebido em: abr/2016

Aprovado em: jul/2016 